ISSN: 2362-1303 (Paper) | eISSN: 2362-1311(Online)

JOURNAL OF ADVANCED ACADEMIC RESEARCH (JAAR)

July 2015

\title{
Role of Ayurvedic Treatment in Minimizing Gastric Cancer Related Complication: A Case Study
}

\author{
Pramod Bhatta $^{1}$ \& Dr. Bhakta Man Shrestha ${ }^{2}$ \\ ${ }^{1} \mathrm{PhD}$ Scholar, Mewar University, Gangrar, Chittorgarh, Rajasthan \\ ${ }^{2}$ Professor, BP Koirala Memorial Cancer Hospital, Bharatpur, Chitwan, Nepal
}

\section{Corresponding Author}

Pramod Bhatta

bhattapra@gmail.com

\begin{abstract}
The patients usually have the trend to come to the Ayurvedic clinic at the final stage when there is no hope of promising treatment from other conventional system of medicine. One of the major causes of reaching to health facility in the final stage might be the geographical difficulty of Nepal. The patients usually come with the hope of getting support for prolonging life with less pain and misery. In this article role of Ayurvedic treatment in gastric cancer cases are presented analytically. The Purpose of this article is to present the cases that are treated in Private Ayrvedic Clinic, and benefitted in cancer related pain, difficulty and complications with Ayurvedic treatment. The method applied in this study was qualitative longitudinal observation, interview based on the initial and final benefit outcome of the treatment from the Ayurvedic clinic. The findings of treatment are found very encouraging in terms of the signs and symptoms and quality of life they were spending. Patients' initial problems found to be reduced by the end of observation and interview. It was found that patients were consistently in contact of doctor for the regular treatment. Patients shared that the treatment was less costly compared to its outcome. It seemed that integration of treatment with conventional treatment method might be quite meaningful to reduce gastric cancer related complications and provide better life to the patients. Extensive research on Ayurvedic treatment is necessary to expand the better services to support patients in meaningful way.
\end{abstract}

\section{KEYWORDS}

Ayurvedic treatment, Gastric Cancer

\section{INTRODUCTION}

Ayurvedic system of medicine is year old medical system being practiced for thousands of year mostly in Nepal and India. The treatment is based holistic approach of medicine and lifestyle modification. Different types of neoplasm are described in Ayurvedic texts some of the explanation resembles to what we called cancer in recent days (Joshi, 1989). The science of 
ISSN: 2362-1303 (Paper) | eISSN: 2362-1311(Online)

JOURNAL OF ADVANCED ACADEMIC RESEARCH (JAAR)

July 2015

Ayurveda is supposed to add a step on to the curative aspects of cancers that have resemblance with clinical entities of arbuda and granthi mentioned in Sushruta samhita (Premalatha Balachandran, 2005). There are different Ayurvedic medicines such as Arogya bardhini, Triphala Guggul, Punrarnawa mandoor etc. are being used for years in the treatment of different cancers (Chaturvedi, 1989). There are different types of cancer where Gastric cancer is one of the common in Nepal. Gastric cancer found to be one of the major fatal cancer reaching to the health facilities at late stage. Early diagnosis of gastric cancer has been very difficult because most patients are asymptomatic in the early stage. Weight loss and abdominal pain and bleeding often are late signs of tumour progression (Shrestha, 2006). The people have come to Ayurvedic treatment when there is no option left after reaching to the hospital at very late stage or advance stage of cancer which makes the treatment difficult along with poor treatment outcome.

From the previous data, there were 14.1 million new cases, 8.2 million cancer deaths 32.6 million people living with cancer (within 5 years of diagnosis) in 2012 worldwide. Eight million (57\%) of new cancer cases, 5.3 million $(65 \%)$ of the cancer deaths and 15.6 million (48\%) of the 5 year prevalent cancer cases occurred in the less developed regions'(WHO, 2012). In Nepal 8.8 per 100,000 gastric cancers found every year. Various parts of body can be affected by cancer and with various types of cancer. Cancer is extraordinary growth of cells which is not controlled by our body system. The cases presented in the article are of Gastric adenocarcinoma, which is a malignant epithelial tumour, originating from glandular epithelium of the gastric mucosa. Stomach cancers are overwhelmingly adenocarcinomas (90\%) (Vinay Kumar, 2010, p. 784). Histologically, there are two major types of gastric adenocarcinoma (Lauren classification): intestinal type or diffuse type. Adenocarcinomas tend to aggressively invade the gastric wall, infiltrating the muscularis mucosae, the submucosa and thence the muscularispropria(Wikipedia, 2015). The prognosis or treatment outcome depends on the stage of cancer which varies depending upon the stages of cancer with respect to its size, invasion and metastasis to the organs. The survival of stomach cancer patient varies between $71 \%$ in early stage 1 st to $4 \%$ in late stage IV (American Cancer Society, 2015).

Overall incidence of primary gastric cancer has steadily declined in the western countries; however it is still prevalent in northern and south Asian countries. The exact prevalence in Nepal is still to be known, however according to the hospital based statistics, it seems to be the commonest cancer in Tribhuvan university teaching hospital followed by lung carcinomas. Over all, the incidence of distal stomach tumors has greatly declined, but reported cases of proximal gastric carcinomas, including tumours at the gastroesophageal junction, have increased. Early diagnosis of gastric cancer has been very difficult because most patients are asymptomatic in the early stage. Weight loss and abdominal pain often are late signs of tumor 
ISSN: 2362-1303 (Paper) | eISSN: 2362-1311(Online)

JOURNAL OF ADVANCED ACADEMIC RESEARCH (JAAR)

July 2015

progression. Chronic atrophic gastritis, Helicobacter pylori infection, chewing tobacco, smoking, heavy alcohol use, and several dietary factors have been incriminated to increase the risks for gastric cancer (Shrestha, 2006). Similarly, an increased risk of stomach cancer is seen in people with diets that have large amounts of smoked foods, salted fish and meat, and pickled vegetables. Nitrates and nitrites are substances commonly found in cured meats. They can be converted by certain bacteria, such as $\mathrm{H}$ pylori, into compounds that have been shown to cause stomach cancer in lab animals(American Cancer Society, 2015).

"Smoking increases stomach cancer risk, particularly for cancers of the upper portion of the stomach near the esophagus. The rate of stomach cancer is about doubled in smokers"(American Cancer Society, 2015). In Nepalese context the increasing gastric cancer trend and Ayurvedic treatment is found very effective for the treatment of gastric cancer so the study is going to explore the outcome of Ayurvedic treatment for minimize the complication of gastric cancer.

\section{METHOD}

The case was from the cancer patients visiting to private Ayurvedic clinic at Bhaktapur, Nepal. The case of gastric cancer was selected and interviewed with the patients and their guardians, along with the observation of Doctor - patient interaction and the patient history was collected from the prescription. Similarly follow up data was also collected from the patients who were available in clinic as well as through the phone conversation from 2013 to 2014. The longitudinal case study method was applied with open ended interview questions. Respondents were selected from the patients of gastric cancer visited to the Ayurvedic clinic at Bhaktapur. The study also used the indirect participant observation to collect the primary data. The respondents were the patients and patients' guardian who provided valuable data for the study. Data analysis was done by using the qualitative method. Case studies were developed from the in-depth interview of patients, guardians and doctor. The ethical approval for this study was taken from the Nepal Health Research Council (NHRC). Verbal consent of Patients, guardians and doctors were also taken very specifically.

\section{RESULT}

\section{Case 1}

The study took the detail interview with Mr. Chhetri of 42 years non vegetarian male of eastern Hilly region of Nepal professionally working as farmer. He came in contact to the clinic at Bhaktapur, referred from the other people who had already received the services of Ayurvedic treatment. 
ISSN: 2362-1303 (Paper) | eISSN: 2362-1311(Online)

JOURNAL OF ADVANCED ACADEMIC RESEARCH (JAAR)

July 2015

\section{$\underline{\text { History of Disease }}$}

During the data collection, the study concerned with the health personnel to know the prevalence of diseases, health seeking behaviour of patients and details of the patients. Initially, study collected the information of history of diseases of patients by observing the prescription and direct interview with patients. As the information given by Mr. Chhetri, he was a patient of stomach cancer suffering for one year. Besides that, he was also suffering from obstruction which caused frequent vomiting and pain. He presented to the clinic with the history of gradual onset of epigastric burning pain and one episode of vomiting with blood eight months back. He said that he had changed bowel habit for more than eight months. Initially he was treated from local clinic with Proton pump inhibitor which relived symptoms for few months then restarted pain and vomiting with foul smell, then he visited to the hospital where he diagnosed to have Cancer stomach with metastasis.

\section{Reasons to visit Ayurvedic Clinic}

Patient was asked about the reason to visit the Ayurvedic clinic because basically, very few people want to take the Ayurvedic services. Mostly people think that Ayurvedic treatment is very traditional and works slowly. The patient said his reason to visit was to get treatment since he already spent long time just for having different medical examination and tests for which cost a lot to him. Later he was explained about the poor prognosis of the disease after the final diagnosis.

\section{Health Status at the Time of Visit (Disease and Treatment)}

The patient weighed $45 \mathrm{Kg}$ and height $5 \mathrm{ft} .4$ inches in first visited was unable to walk, dizzy with continuous vomiting, could not eat any food, his vital signs were normal the patient received treatment with classical Ayurvedic medicine from 2013 at the clinic.

\section{Health Behavior}

The study talked about the health behavior of patients to explore the possible contributing factors which might have played role on producing disease. He said that he was smoking cigarettes for more than 25 years not less than 20 sticks per day. He had to work with empty stomach for long time while he worked as local leader. He also said that he drank too much tea and also enjoyed junk food before having health problem.

\section{Advice and Treatment}

The study collected the information about the advice and treatment given by the health personnel which was about food habit, behavior. He was advised to take small amount of food at once and increase the frequency of eating, to take soft foods without spices, not to smoke or drink alcohol, adequate rest and sleep, increase amount of fluid drink, avoid sour foods and take prescribed medicine regularly. 
ISSN: 2362-1303 (Paper) | eISSN: 2362-1311(Online)

JOURNAL OF ADVANCED ACADEMIC RESEARCH (JAAR)

July 2015

The respondent shared his experiences by saying that 'he followed the advice and took treatment regularly'.

\section{Outcomes after Treatment}

The patient continuously took the medicine from date July 2013 then after gradually he felt relief in his pain, he had no vomiting, bowel was regular, and occasionally he felt nausea for which he took antiemetic medicine. He said that he has problem to stay here in Kathmandu so he will stay for few days to get treatment then will go to his home where he will continue the medications. Later he mentioned that he had difficulty to come Kathmandu frequently but he continued taking medicine. He visited the clinic for follow up after three months he was happy and was much better in observation; he mentioned that he was far better than before. From the prescription his vital signs were normal. He continued treatment later. At last phone interview with the patient he said he was taking medicine and enjoying his normal life until the date July 2014.

\section{Patients' Perception on Visiting Ayurvedic Clinic}

Normally in first visit the patients want to observe the clinic and know the treatment method and analyze whether they will be benefited from the treatment or not. The patient answered about the reason for visiting Ayurvedic clinic was to observe and share their previous experience from other hospital and to seek advice and treatment support from the clinic. They also heard regarding cancer treatment and side effects, expenses and treatment poor treatment outcome so they visited to the clinic. The perceive that the Ayurvedic treatment were less costly, having none or very less side effects and easy to take while staying at home. They (patient and guardian) also said that they came for the treatment with the hope that probably will prolong their quality life if cannot cure at all. In other hand they want to avoid postsurgical problem and complications.

\section{Outcome and Present Situation}

During the initial visit patient was very weak, pallor which he said in follow up visit patient suffered less and stayed with family. He mentioned that he had less pain, stopped vomiting, can sleep well, and went to stroll around, had good appetite enjoyed his normal life in the village.

\section{Future Plan and Suggestion}

When he was asked for any suggestions for other people from his experience he said that "suffering usually comes from our behavior so better to modify lifestyle, live happy, eat timely, stop smoking and drinking and early checkup for proper diagnosis of the health problem to prevent disease."

\section{Case 2}


ISSN: 2362-1303 (Paper) | eISSN: 2362-1311(Online)

JOURNAL OF ADVANCED ACADEMIC RESEARCH (JAAR)

July 2015

The study took the detail interview with sixty nine years old Mr. Bhandari resident of eastern Terai region of Nepal professionally working as farmer. He mentioned that he was migrated to India where he had to face very stressful lifestyle during his youth time then he moved to Terai of Nepal. He came in contact to the clinic at Bhaktapur, referred from the other Ayurvedic clinic outside Kathmandu valley.

\section{History of Disease}

During the data collection, the study concerned with the health personnel's view to know the prevalence of diseases, health seeking behavior of patients along with the patient's guardian. Initially, study collected the information of history of diseases of patients by observing the prescription and direct interview with patients. As the information given by Mr. Bhandari, he was a patient of stomach cancer suffering for one year (August 2013, when problem started). Besides that, he was also suffering from obstruction which caused frequent vomiting and pain. He presented to the clinic with the history of abdomen pain associated with yawing. Initially he was treated from local hospital with Proton pump inhibitor which relived symptoms for few months then restarted pain and vomiting then he said that he went to Bharatpur cancer hospital from advice of local doctor after doing endoscopy. At Bharatpur cancer hospital he diagnosed to have Cancer stomach with metastasis. He also mentioned that it took long time for diagnosis and he also finished his money just for making diagnosis.

Histopathological examination showed moderately differentiated tubular adenocarcinoma.

\section{$\underline{\text { Reasons to Visit Ayurvedic Clinic }}$}

Patient was asked about the reason to visit the Ayurvedic clinic, since very few people want to take the Ayurvedic services. He visited the clinic with the hope of prolonged, easy and painless life through the Ayurvedic treatment and also said the system of medicine is year old and of our own origin so he wished to take Ayurvedic treatment. He said that "he don't want to have surgery at this age."

Mostly people think that Ayurvedic treatment is very traditional it works slowly. The patient said his reasons to visit was that the examination and test cost a lot and spent more time just for investigation, his age was seventy and he thought not to go for surgery which also was not sure for the prolongation and pain minimizing in other hand treatment was expensive, rather than just to survive his remaining life with ease. Apart from that he mentioned, he was already seventy years old and did not want go for surgery with uncertain outcome.

\section{Health Status at the Time of Visit (Disease and Treatment)}

The patient weighed $43 \mathrm{Kg}$ and height $5 \mathrm{ft} .3$ inches. During the initial observation and interview he had difficulty walking, dizzy and had high fever, with continuous vomiting, could not eat any food. From prescription his blood pressure was slightly low, other vital signs were 
ISSN: 2362-1303 (Paper) | eISSN: 2362-1311(Online)

JOURNAL OF ADVANCED ACADEMIC RESEARCH (JAAR)

July 2015

normal. The patient received treatment with classical Ayurvedic medicine from 2013 at the clinic.

\section{Health Behavior}

The study talked about the health behavior of patients to explore the possible contributing factors which might have played role on producing disease. He said he was smoking cigarettes for more than 25 years and smoking 30-40 cigarette sticks per day along with chewing tobacco for more than 40 years. He also used to drink alcohol during his youth period he drank for around 30 years. He uses to eat meat almost every day. He also said that he drank too much tea and also enjoyed junk food before having health problem. The family member mentioned that he still continued chewing tobacco.

\section{Advice and Treatment}

The study collected the information about the advice and treatment given by the health personnel which was about food habit, behavior. He was advised to take small amount of food at once and increase the frequency of eating, to take soft foods without spices, not to smoke or drink alcohol, adequate rest and sleep, increase amount of fluid drink, avoid sour foods. He said that he was also advised to consult local health facilities for symptomatic relief in case of emergency.

The respondent shared his experiences by saying that 'he followed the advice and took treatment regularly.

\section{Outcomes after Treatment}

The patient continuously took the medicine from date August 2013 then after gradually he/she felt relief in his pain, he had no vomiting, bowel was regular, and occasionally he felt nausea for which he took antiemetic medicine and proton pump inhibitor. He had to visit local hospital for two times which he mentioned during his follow up interview. He gained weight 2-3 kg in 3 months. As the respondent was from out of valley he continued treatment staying at his home and continuously updated his status. Later he mentioned that he had difficulty to come Kathmandu frequently but he continued taking medicine. He visited the clinic for follow up after months he was happy and was much better in observation; he mentioned that he was far better than before. From the prescription his vital signs were normal. He continued treatment later. During the interview in July 2014 with the patient he said he was taking medicine and enjoying his normal life.

\section{Patient's Perception on Visiting Ayurvedic Clinic}

When he was asked the reason of visiting the clinic he mentioned that he will get the better treatment from the clinic. He also mentioned not go for surgery and expensive treatment rather 
ISSN: 2362-1303 (Paper) | eISSN: 2362-1311(Online)

accept Ayurvedic treatment he also said that when the Ayurvedic doctor asked to visit cancer hospital for further advice on treatment he refused to go there. He wished to get the treatment whatever will be from this clinic. He said he had already spent a lot of money going in different hospitals. The perceive that the Ayurvedic treatment were less costly, having none or very less side effects and easy to take while staying at home. They (patient and guardian) also said that they came for the treatment with the hope that probably will prolong their quality life if cannot cure at all. In other hand they want to avoid post surgical problem and complications.

\section{Outcome and Present Situation}

At first interview observation during the initial visit patient was very weak, pallor which he said in follow up visit patient suffered less and stayed with family. He mentioned that he had less pain, stopped vomiting, can sleep well, and went to stroll around, had good appetite enjoyed his normal life in the village. He was able to do simple household works and enjoying with grand children.

\section{Future Plan and Suggestion}

He said that he will continue taking medicine and will modify the habit for being healthy control disease and also mentioned. When he was asked for any suggestions for other people from his experience he said that "suffering usually comes from our behavior so better to modify lifestyle, live happy, eat timely, better not to eat meat quite often, stop smoking and drinking and early checkup for proper diagnosis of the health problem to prevent disease."

\section{$\underline{\text { Case } 3}$}

The study took the detail interview with seventy years old Mr. Raut resident of Bhaktapur of Kathmandu valley professionally working as retired service holder and came in contact to the Ayurvedic clinic at Bhaktapur, referred from the other people who received service from the clinic.

\section{History of Disease}

During the data collection, the study concerned with the health personnel's view to know the prevalence of diseases, health seeking behavior of patients along with the patient's guardian. Initially, study collected the information of history of diseases of patients by observing the prescription and direct interview with patients and patient's guardian. As the information given by Mr. Raut, who had very short history of health problem of three months when he started vomiting every alternate day then went to hospital and diagnosed to have stomach cancer (January 2014, when problem started). The problem started due to obstruction which caused frequent vomiting and pain. He presented to the clinic with the history of loss of appetite and blood in stool. Initially he was treated from cancer specialist at cancer hospital for symptomatic relief counseled about prognosis of the disease. 
ISSN: 2362-1303 (Paper) | eISSN: 2362-1311(Online)

JOURNAL OF ADVANCED ACADEMIC RESEARCH (JAAR)

July 2015

Histopathological examination showed diffuse type gastric adenocarcinoma.

\section{Reasons to visit Ayurvedic Clinic}

Patient was asked about the reason to visit the Ayurvedic clinic the patient said he was advised to visit the Ayurvedic clinic from one of his friend who was taking treatment from the clinic after learning about the poor prognosis of his cancer. He also mentioned there was only less hope of getting better support from the other hospital as the disease already spread. Only hope was surgery but he don't like to go for surgery because of poor prognosis. He visited the clinic with the hope of prolonged, easy and painless life through the Ayurvedic treatment and also said the system of medicine is year old and of our own origin so he wished to take Ayurvedic treatment. He said that "he don't want to have surgery at this age."

\section{Health Status at the Time of Visit (Disease and Treatment)}

The patient weighed $47 \mathrm{Kg}$ and height $5 \mathrm{ft}$. 5 inches. During the initial observation and interview he had difficulty walking, dizzy and had high fever, with continuous vomiting, could not eat any food. From prescription his blood pressure was slightly low, other vital signs were normal. The patient received treatment with classical Ayurvedic medicine from 2014 at the clinic.

\section{Health Behavior}

The study talked about the health behavior of patients to explore the possible contributing factors which might have played role on producing disease. He said he was smoking cigarettes for around 60 years and smoking more than 20 cigarette sticks per day. He also used to drink approximately $600 \mathrm{ml}$ alcohol until few days back for 40 years. He was eating meat almost every day with excessive spice and also consumed excessive amount of old pickle. He also said that he drank too much tea 8- 10 cups per day. He also spent aggressive and stressful life during his youth.

\section{Advice and Treatment}

The study collected the information about the advice and treatment given by the health personnel which was about food habit, behavior. He was advised to take small amount of food at once and increase the frequency of eating, to take soft foods without spices, not to smoke or drink alcohol, adequate rest and sleep, increase amount of fluid drink, avoid sour foods. He said that he was also advised to consult local health facilities for symptomatic relief in case of emergency.

The respondent shared his experiences by saying that 'he followed the advice and took treatment regularly.

\section{$\underline{\text { Outcomes after Treatment }}$}


ISSN: 2362-1303 (Paper) | eISSN: 2362-1311(Online)

JOURNAL OF ADVANCED ACADEMIC RESEARCH (JAAR)

July 2015

The patient continuously took the medicine then gradually he/she felt relief he less frequency of vomiting, bowel was regular, and occasionally he felt nausea for which he took antiemetic medicine and proton pump inhibitor along with Ayurvedic treatment. He visited the clinic for follow up every month and interviewed at the same time. He was happy and much better in observation; he mentioned that he was far better than before. From the prescription his vital signs were normal. He continued treatment later. During the interview in December 2014 with the patient he said he was taking medicine and enjoying his life in better way.

\section{Patient's Perception on Visiting Ayurvedic Clinic}

When he was asked the reason of visiting the clinic he mentioned that he will get the better treatment from the clinic. He also mentioned not go for surgery and expensive treatment rather accept Ayurvedic treatment. He also said that when the Ayurvedic doctor asked to visit cancer hospital for further advice on treatment he refused to go there. He wished to get the treatment whatever will be the result from the clinic. They (patient and guardian) also said that they came for the treatment with the hope that probably will prolong their quality life if cannot cure at all. In other hand they want to avoid post surgical problem and complications.

\section{Outcome and Present Situation}

At first interview observation during the initial visit patient was very weak, pallor which he said in follow up visit patient suffered less and stayed with family. He mentioned that he had less pain, stopped vomiting, can sleep well, and went to stroll around, had good appetite enjoyed his normal life in the village. He was able to do simple household works and enjoying with grand children.

\section{Future Plan and Suggestion}

He said that he will continue taking medicine and will modify the habit for being healthy control disease and also mentioned. When he was asked for any suggestions for other people from his experience he said that "suffering usually comes from our behavior so better to modify lifestyle, live happy, eat timely, better not to eat meat quite often, stop smoking and drinking and early checkup for proper diagnosis of the health problem to prevent disease."

\section{Finding from Observations}

All the patients were benefited in terms of their treatment outcome, all got relief from their symptoms of vomiting, fever, loss of appetite, and stay with the family and they were able to involve in normal life work.

From above cases few common similarities were observed mostly related to the behavior of the patient.

- All patients were chronic smokers who smoked for more than more than 20 sticks for

25 years case 1, 30-40 sticks per day for 25 years similarly 20 sticks per day for 60 
ISSN: 2362-1303 (Paper) | eISSN: 2362-1311(Online)

JOURNAL OF ADVANCED ACADEMIC RESEARCH (JAAR)

years, similarly Case 2 and 3 used to drink alcohol heavily. Food habit of all cases were also similar they all use to drink tea in excess, use excess spice and all were non vegetarian.

- All patients did not take seriously about their health problem earlier until it really bothered them too much.

- All of them spend stressful life in their youth life. They all were drinking tea in excess with and had no particular eating time.

- The patient perceived that Ayurvedic treatment has almost no side effects if don't do good but some where they have faith on this ancient treatment system.

- They all suffered from poor to moderately differentiated gastric adenocarcinoma.

\section{DISCUSSION}

Ayurvedic system of medicine is ancient system of medicine where description of neoplasm (arbuda) and its treatments are explained (Ref: Susrut Nidan Sthan, 1991).There are very few Ayurvedic research in cancer treatment but even then if receive adequate support and research many people may benefit from its support. In Nepalese context also it was found from the study that Ayurvedic treatment is also found effective to minimize the health related complication.

The knowledge and management of the disease, cancer was not unknown to the ancient surgeons of India. Though the Sanskrit equivalent for this word is not found in Ayurvedic literature, diseases having the signs and symptoms similar to those of Cancer are discussed in various contexts (G. C. PRASAD, January 1982).

At present day conventional medicine is mostly used to treat cancers with some case of promising outcome like skin cancer, breast cancer, leukemia, lymphoma etc. if detected earlier but poor prognosis in case of lung cancer, and some case of colon cancer. Based on opinion of Reason wilken there is need for alternative and less toxic therapies for head and neck squamous cell carcinoma. As a natural product, curcumin is both nontoxic as well as diversified in its inhibitory effects on a multitude of pathways involved in carcinogenesis and tumor formation (Reason Wilken, 2011). From this it is evident that the herbs and herbal product found as anti cancerous agent, which can be used to treat cancers effectively after doing extensive research.

One of the example based on Reason Wilken et al Curcumin (Curcuma longa) which is commonly known as turmeric has been used extensively in Ayurvedic medicine for centuries, as it is nontoxic and has a variety of therapeutic properties including anti-oxidant, analgesic, anti-inflammatory and antiseptic activity. It contains diferuloylmethane a polyphenol derivative found to possess anti-cancer activities via its effect on a variety of biological pathways 
ISSN: 2362-1303 (Paper) | eISSN: 2362-1311(Online)

JOURNAL OF ADVANCED ACADEMIC RESEARCH (JAAR)

involved in mutagenesis, oncogene expression, cell cycle regulation, apoptosis, tumorigenesis and metastasis in recent studies. Similarly it showed anti-proliferative effect in multiple cancers (Reason Wilken, 2011). The practice of Ayurvedic clinic also was based on use of similar type herbs and herbal product in combination and the outcome was found very effective.

According to Roophesh Jain, "Cancer is one of the most deadly challenges spreading drastically in $21^{\text {st }}$ century, has now officially become the most dangerous killer in the world according to the World Health Organization. Who can deny the fact that cancer is related to adversary of modernization and advanced pattern of irregular and stressed life dominated by Western medicine. Scientists are making their best efforts to fight this disease; however the sure-shot cure is still awaited" (Roopesh Jain, 2010). In this context Ayurvedic treatment method provide both medicines and modification in life style which includes Yoga, detoxification of body, stress management, and modified food habit which provide holistic care of the patient for better outcome. In the same line, the study also found that mostly doctors advised to continue medicine as prescribed by doctor avoid spicy food and alcoholic beverage and hot foods and manage regular Yoga and meditation practices.

According to Dr C P Shukla, Ex Dean of Gujrat Ayurveda University, Jamnagar, Gujrat, the patient comes to the Ayurvedic health personnel in the following reasons first if there is no benefit from conventional treatment, second the patients with complications and adverse effects of modern treatment, third that patients who feared of complications of modern medicine and fourth type of patients who had faith in Ayurveda (Shukla, 1989). Similar types of answers found in the interview with patient who visited the Ayurvedic clinic. Mostly in Nepalese context, study found that patients visit in last stage of complication when they lost the hope of happiness from the other types of treatment.

As advised by Premlatha Balchandran in the article that an integrated approach is needed to manage cancer using the growing body of knowledge gained through scientific developments. Thousands of herbal and traditional compounds are being screened worldwide to validate their use as anti-cancerous drugs (Premalatha Balachandran, 2005). Nepal is also rich in anti-cancer natural herbs that can be used for the treatment of cancer. In study also found that, Doctors were using the various Ayurvedic medicine and herbal preparation such as; Arogya Bardini bati, Purnawa mandur, Abharak Vasma, Turmeric, Tinosphora cordifolia, Aamala etc. all these medicines and herbs were found effective in treatment of Gastric Cancer.

\section{CONCLUSION}

From analysis, the conclusion can be drawn that people usually visit Ayurvedic clinic only at very late stage and when there was very little hope of better care in other health facilities. It was very difficult to treat in the last stage although the treatment result seemed quite encouraging in supportive care. All the patients were referred either from clinic or the people who received treatment from the clinic before. Initially the patient visit to observe the clinic for Vol. 2. No. II

www.phdcentre.edu.np 
ISSN: 2362-1303 (Paper) | eISSN: 2362-1311(Online)

JOURNAL OF ADVANCED ACADEMIC RESEARCH (JAAR) July 2015

the kind of support they can get from Ayurvedic clinic. It was perceived while talking to the patient that the patient came with the hope of getting better (health benefit) from the clinic. The patients were diagnosed from other hospital and received partial treatment. Treatment outcome was not satisfactory in terms of prognosis. The patients either came to avoid the surgical and painful management with poor prognosis of disease or to minimize the adverse effect of modern treatment. They also perceived that the treatment was less costly.They had fear of excessive expense with uncertain longevity and quality of life. It was observed that the number of patients visit in Ayurvedic clinic was comparatively less than the modern clinic but the majority of patients were found happy after getting the treatment. Integrating the Ayurvedic treatment with modern treatment can give better result in treatment and cure of patients. So it is strongly recommended to conduct the intensive research on efficacy of Ayurvedic treatment in Cancer or other health related complications. Government should take care of available herbs and Ayurvedic medicine which are described in Ayurvedic text.

\section{ACKNOWLWDGEMENT}

I would like to extend my sincere thanks to $\mathrm{Mr}$ Tej Bdr. Karki for his valuable support. I like to thank to Nepal Health Research Council (NHRC) to provide the ethical approval to conduct this study. I like to thank to Southwestern Centre for PhD Studies for providing the platform for study. 
ISSN: 2362-1303 (Paper) | eISSN: 2362-1311(Online)

JOURNAL OF ADVANCED ACADEMIC RESEARCH (JAAR)

July 2015

\section{REFERENCES}

American Cancer Society. (2015, March 16). Retrieved Jun 19, 2015, from American Cancer Society: http://www.cancer.org/cancer/stomachcancer/detailedguide/stomach-cancersurvival-rates

American Cancer Society. (2015, March 16). Retrieved Jun 20, 2015, from American Cancer Society: http://www.cancer.org/cancer/stomachcancer/detailedguide/stomach-cancerrisk-factors

Chaturvedi, S. (1989). Treatment of cancer (Swanubhut Cancer Rog Chikitsa). Ayurveda Vikas, 23-25.

G. C. PRASAD, M. S. (January 1982). Ancient Science of Life, Vol No. I No.3, Pages 172 176, 172 - 176.

Joshi, A. (1989, November). Arbud banam Cancer. Ayurved Vikas, 113-120.

Premalatha Balachandran, R. G. (2005). Cancer-an ayurvedic perspective. Pharmacological Research, 19-30.

Reason Wilken, M. S. (2011). Curcumin: A review of anti-cancer properties and therapeutic activity in head and neck squamous cell carcinoma. molecular cancer.

Roopesh Jain, S. K. (2010, Nov-Dec). Ayurveda and cancer. Pharmacognosy Res. ; 2(6):, $393-$ 394.

Shrestha, M. ( 2006). Gastric cancer: diagnosis and treatment options. Journal of Institute of Medicine, Vol 28( No 3).

Shukla, C. P. (1989). Ayurveda Chikitsa Shutra. Ayurveda Vikas, 26.

Vinay Kumar, A. K. (2010). Pathologic Basis of Disease (8th ed.). Saunders Elsevier.

WHO. (2012). Retrieved Jun 19, 2015, from International Agency for Research on Cancer: WHO: http://globocan.iarc.fr/Pages/fact_sheets_cancer.aspx

Wikipedia. (2015, Jun 16). Retrieved Jun 19, 2015, from Wikipedia, the free encyclopedia: https://en.wikipedia.org/?title=Stomach_cancer\#Histopathology 